\title{
Experimental investigation on stacking sequence of Kevlar and natural fibres/epoxy polymer composites
}

\author{
Murali Banu $^{1 *}$ (D), Vijaya Ramnath Bindu Madhavan² (D), Dhanashekar Manickam³ ${ }^{3}$ \\ and Chandramohan Devarajan ${ }^{3}$ (D)
}

\author{
'Department of Mechanical Engineering, Anna University, Chennai, Tamil Nadu, India \\ ${ }^{2}$ Department of Mechanical Engineering, Sri Sairam Engineering College, Chennai, Tamil Nadu, India \\ ${ }^{3}$ Department of Mechanical Engineering, St. Peter's Institute of Higher Education and Research, Chennai, \\ Tamil Nadu, India \\ *bmprojectss@gmail.com
}

\begin{abstract}
This paper investigates the stacking sequence of combined natural and synthetic fibres reinforced epoxy composites for better mechanical properties. The hybrid composites fabricated using vacuum assisted compression molding process with the natural and synthetic fibres layered in three different sequences such as type I, type II and type III where the synthetic fibers were placed alternatively. The ultimate tensile strength of composite type III was increased by $12 \%$ and $30 \%$ when compared to composite type I and type II respectively. The flexural test results showed that composite type III have better flexural strength $223 \mathrm{MPa}$ which is $13 \%$ and $11 \%$ greater than composite type I and type II respectively. Overall, it can be declared that the composite type III shows better tensile, and flexural properties i.e., the composite with aloe vera and palmyra palm fibres have better wettability with the matrix when compared to bamboo fibre.
\end{abstract}

Keywords: aloe vera fibre, bamboo fibre, epoxy resin, Kevlar fibre, palmyra palm fibre.

How to cite: Banu, M., Madhavan, V. R. B., Manickam, D., \& Devarajan, C. (2021). Experimental investigation on stacking sequence of Kevlar and natural fibres/epoxy polymer composites. Polímeros: Ciência e Tecnologia, 31(1), e2021004. https://doi.org/10.1590/0104-1428.04320

\section{Introduction}

In this world, natural fibre-reinforced polymer composites are being most widely considered as a potential area for researchers and research opportunities for producing advanced polymer composites. Natural fibre ${ }^{[1]}$ such as coconut coir, sisal, banana, kenaf, hemp, pineapple leaf fibre, bamboo, bagasse and jute are widely used as reinforcements in polymer composites and the detailed applications of each fibres in automobile and other industries are listed by Mohammed et al. ${ }^{[2]}$. Renewable resource consumptions afford the progressive ways for sustainability of ' green' environment conditions ${ }^{[3,4]}$. Composites having multi reinforcements are termed as hybrid composites and mostly the multi reinforcements are either natural or synthetic fibres else a combination of both. The hybrid composites that take the most advantage of the best properties of the constituents, and thereby an ideal, greater but economical composite can be increased ${ }^{[5]}$. The elements of a composite, such as fibres and matrix, affect the mechanism working in the composites during loading, failure modes, damage progression, and finally the strength ${ }^{[6]}$. Effective hybridization of woven natural fibre fabrics with carbon, E glass, aramids, basalt and Kevlar fibres are the vital way to characterize the best bio-composites ${ }^{[7,8]}$.

Chandramohan et al..$^{[9]}$ investigated that the relative hybrid Sisal/ Rosell/ Banana fibre reinforced epoxy composites and illustrated that composites are greater for successful tensile loading and flexural loading. Srinivasan et al. ${ }^{[10]}$. Concluded that hybrid composite has potential properties than single glass fibre reinforced composite beneath collision and flexural loads and also fibre strength is significantly linked with the positioning and orientation of fibres. Vijaya Ramnath et al. ${ }^{[1]}$ have studied the effects of twisting the natural fibres (kenaf and neem) and fibre orientation on mechanical properties of composites. The twisted fibre with $45^{\circ}$ orientation produced better mechanical properties. Mohammed et al. ${ }^{[2]}$ have reviewed the effect of chemical treatment on natural fibres and concluded that it improved adhesion between the fibre surface and the matrix which ultimately enhanced physicomechanical and thermochemical properties of the natural fibre reinforced polymer composites (NFRPCs).

Yan et al. ${ }^{[12]}$ reported that chemical treatment of natural fibre reduces the stiffness and toughness but when treated with Silane (Si) an significant improvement in tensile strength of flax fibres was observed and this was due to silane being grafted with carbonyl chain between microfibrils. Increase in ratio of cellulose in the natural fibre enhances the mechanical properties. Synthetic and natural fibres are combined to increase the tensile strength of the high density polyethylene (HDPE) composites ${ }^{[13]}$. Combined effects of chemical treatment of fibres and inclusion nano-fillers have improved the dynamic mechanical properties of natural 
fibre reinforced polymer composites ${ }^{[14]}$. Chaitanya et al. ${ }^{[15]}$ investigated the effect of alkaline treatment $(5 \%$ concentration of $\mathrm{NaOH}$ ) on surface modifications of aloe vera fibres and concluded that there was an improvement in thermal stability, tensile, compression and flexural properties while impact strength decreased as the alkaline treatment removed the lignin and waxes from the fibre surface.

Sampath et al. ${ }^{[16]}$ have concluded that inclusion of nano-fillers increases the mechanical properties of the composites by strengthening the matrix yield strength. Karaduman et al. ${ }^{[17]}$ have investigated the effect of stacking sequence on chemically treated flax/jute fibre reinforced hybrid composites by means of tensile and flexural tests. Nunes et al. ${ }^{[18]}$ stated that fibre orientation, laminate sequence and surface waviness have significant effect on the flexural strength of the composites. $\mathrm{Li}$ et al. ${ }^{[19]}$ suggested the hybrid polymer composites with windmill palm fibre and a strong-brittle fibre (such as flax or jute), can produce high elongation properties which allows better stress transfer, and increase the effective fibrematrix adhesion.

Dynamic mechanical analysis of natural fibre reinforced polymer composites were studied to understand the viscoelastic behaviour. Weight/volume percentages, fibre size, fibre shape, fibre orientation and stacking sequence of hybrid laminates influence the dynamic mechanical properties ${ }^{[14]}$. The basic dynamic mechanical analysis output parameters such as storage modulus, loss modulus and damping factor $(\tan \delta$ ) with respect to temperature enunciate about matrix-fibre interfacial bonding ${ }^{[20]}$. Gupta et al ${ }^{[21]}$ studied and concluded that the dynamic mechanical performance of hybrid epoxy composite (jute + sisal fibres) was better than plain jute and sisal composite, which shows the effect of hybridization of natural fibre reinforced polymer composites as an advantage.

To the best of the author's knowledge, no peer reviewed research articles were made to experimentally study the effect of Kevlar with natural fibre reinforced epoxy composites. Only a few researchers have focused on stacking arrangements of hybrid natural fibres influence on the mechanical and dynamic properties of the polymer composites. The goal of this research was to investigate the optimal stacking sequence of dual natural fibres in kevlar/epoxy composites.

\section{Materials and Methods}

Aramid is abbreviated from the word aromatic polyamide (poly-p-phenylene terephthalamide) which is also called as Kevlar and it is the most widely used organic fibre in the aerospace applications. Researchers made efforts to utilize many compostable and biodegradable fibres extracted from the plants as reinforcement materials in the polymer for the development of advanced composites. In this research work, the natural fibres such as aloe vera, bamboo and palmyra palm along with the Kevlar fibre with the density of 1.4, $0.9,1.3$ and $1.43 \mathrm{~g} / \mathrm{cm}^{3}$ respectively, were used in a defined stacking sequence in fabricating the hybrid composites. The thickness of Kevlar fibre mat and all natural fibres was $0.3 \mathrm{~mm}$ and $0.35 \mathrm{~mm}$ respectively. Epoxy resin (LY556) and hardener (HY951) of density $1.15-1.20 \mathrm{~g} / \mathrm{cm}^{3}$ and $0.97-$ $0.99 \mathrm{~g} / \mathrm{cm}^{3}$ respectively were used as the matrix. Epoxy has excellent moisture repellent qualities when utilized in polymer composites. The natural fibres were alkaline treated in $2.5 \mathrm{ml}$ $\mathrm{NaOH}$ solution for $6 \mathrm{hr}$ at room temperature and dried to remove the wax and oils available on the external surface of natural fiber. Then natural fibres were again treated with $2.5 \mathrm{ml} \mathrm{NaOH}$ solution, boiled at $75^{\circ} \mathrm{C}$ for $3 \mathrm{hr}$ to remove a certain rate of lignin and hemicellulose which enhances the matrix-fiber interface and ensures better adhesion. Increase in $\mathrm{NaOH}$ solution concentration causes defibrillation and pore formation on the fiber surface. Now the natural fibers are washed with distilled water 3-4 times for the deletion of $\mathrm{NaOH}$ solution. Later the natural fibres neutralization was achieved by treating in $2 \% \mathrm{HCl}$ solution boiled at $75^{\circ} \mathrm{C}$ for $4 \mathrm{hr}$ which removes residual hydroxyl. Finally fibres were immersed in $1 \%$ ethanol and dried at $110{ }^{\circ} \mathrm{C}$ for $10 \mathrm{hr}^{[16]}$.

The hybrid composites were fabricated using vacuum assisted compression molding process, which completely eliminates the defects produced in hand lay-up technique and it is reliable when compared to other techniques namely resin transfer molding and Pultrusion ${ }^{[11]}$. The diagrammatic representation of the vacuum assisted compression moulding process is shown in Figure 1a-c. Three types of composites were fabricated based on the sequence of layering the synthetic

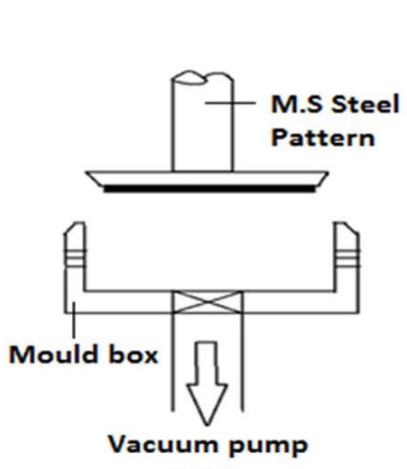

(a)

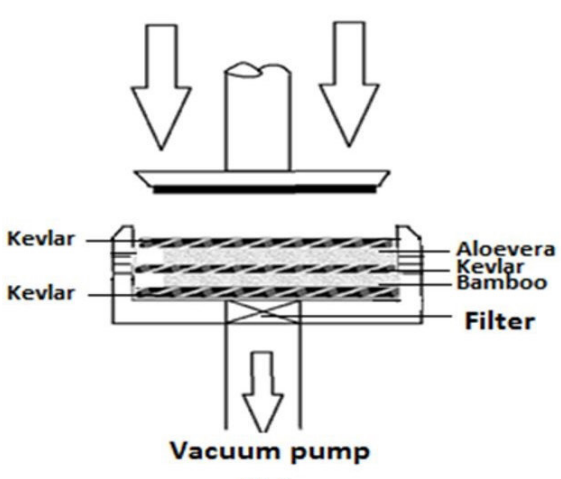

(b)

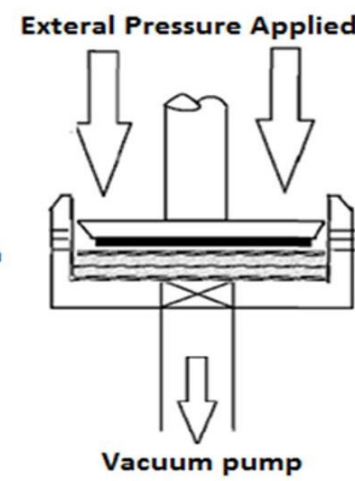

(c)

Figure 1. Sequence involved in Vacuum assisted compression moulding; (a) placement of mold and pattern; (b) placement of fibres in mold; and (c) external application of compression pressure. 
Kevlar fibre and dual natural fibres where the number of layers were fixed to be 5 layers in common and the matrixreinforcement ratio to be 60:40. The resin hardener ratio of 10:1 was followed to enhance the interfacial bonding between the fibres. Initially the mould is vacuumed prior to layering the fibre mat in the given sequence as mentioned in the Figure 2a. The matrix is introduced into the mould and the preform is compressed by applying external pressure. The mold is left idle for 8 hours for complete drying and then the fabricated composites are ejected from the mould. The photographs of fabricated composites shown in Figure $2 \mathrm{~b}$.

\subsection{Testing methods}

The tensile test is carried out using a Universal Testing machine for the fabricated composite laminate blanked as per ASTM D638 standards as shown in Figure $3 \mathrm{a}^{[22]}$. The test samples were firmly clamped to the fixture to ensure there is no slip during the application of load and the traverse speed was maintained at $2.5 \mathrm{~mm} / \mathrm{min}$. The tensile results reveal the bond strength of different fibre layers and the load bearing capacity of the composite material is examined.

The ASTM D790 standards was followed for Flexural analysis of the composite sample using the Universal Testing machine with the specimen dimensions as given in Figure 3b. The flexural test results aids to identify the interlaminar shear strength as the concave shape formation induces more shear in between the lamina. The fracture surface analysis highlights the failure mechanisms and the reasons. All the testing were carried out at standard atmospheric temperature. The dynamic mechanical analysis was performed using DMA Q800 V20.6 build 24 at Institute of Plastic Technology, Chennai, India according to ASTM D4065- $01^{[23]}$. The test specimen was prepared with the

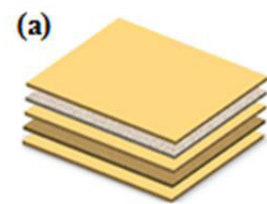

TYPE.1

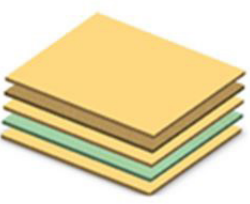

TNPE-II

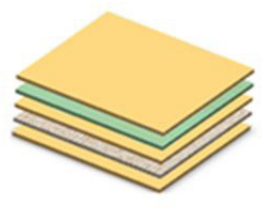

TNPE-m

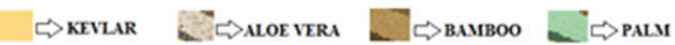

(b)

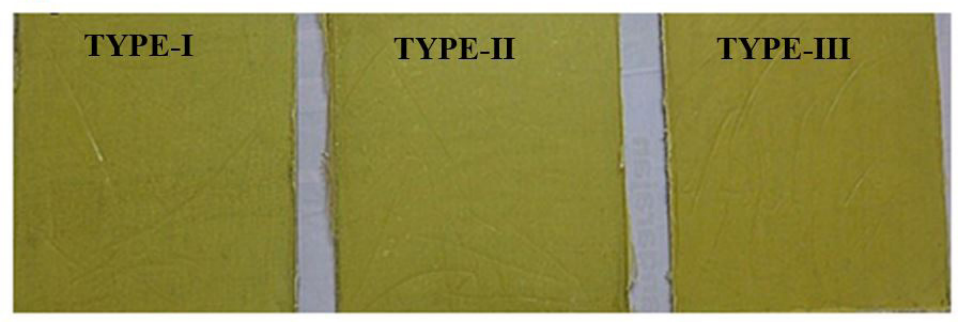

Figure 2. (a). 3D design of layering the fibres in three different types; (b) Photographs of fabricated composites.

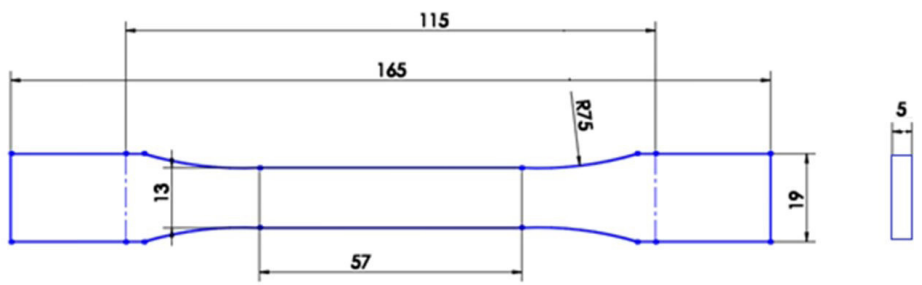

(a) Tensile test specimen

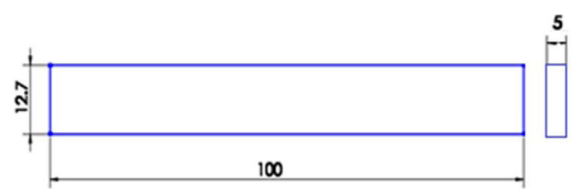

(b) Flexural test specimen

Figure 3. 2D diagrams of composite dimensions machined for various testing according to the ASTM standards (All Dimensions are in mm). 
dimensions of $65 \mathrm{~mm} \times 12.7 \mathrm{~mm} \times 5 \mathrm{~mm}$. All the tests were performed under bending mode at a frequency of $1 \mathrm{~Hz}$ and at specific temperatures range from $28^{\circ} \mathrm{C}$ to $200{ }^{\circ} \mathrm{C}$ with a heating rate of $4{ }^{\circ} \mathrm{C} / \mathrm{min}$.

\section{Results and Discussion}

\subsection{Tensile strength}

The tensile test results for the fabricated three types of hybrid composites are given in Table 1 and the values are averaged from 3 readings for each type of composite. Figure 4 shows the type III (Palm + Aloe vera fibres) composite having a higher tensile strength of $128 \mathrm{MPa}$ with an elongation of $18 \%$. This is due to the increase in wettability of the natural and synthetic fibre- matrix interface. The alkaline treatment of palm and aloe vera fibre, removes the lignin and waxes off the fibre surface ${ }^{[15]}$. Simultaneously the fibre surface is roughened enabling the strong interface bond strength between the fibres and the matrix. In case of bamboo fibres, the material properties are directional based (compression force applied perpendicular to the longitudinal direction, undergoes frequent random break of bond in tangential direction because of the weaker bond between fibres) ${ }^{[24]}$.

The density of the bamboo fibre is lesser when compared to aloe vera and palm fibre, this is one of the reasons for the composites reinforced with bamboo fibre exhibited a variation in load distribution when subjected to tensile test. The bamboo reinforced composites failed due to the higher concentration of inter laminar shear stress at the fibre-matrix interface and the initial failure of bamboo fibre is observed in the stress vs. strain plot (as shown in Figure 4), with a deflection. As a result, the bamboo fibre reinforced composites experienced failure earlier to the other composites.

\subsection{Flexural strength}

Flexural strength of the fabricated composites is tested to understand the strengthening mechanism between the fibre and the matrix interface. Due to the mixed combinations of stresses and the different elastic properties of the stacked fibre laminate, estimation of the flexural strength is important in deciding the end application. Similar to the ultimate tensile strength, the flexural behaviour of the composite depends on the orientation of the fibre and the fibre laminate stacking sequence.

Application of load in the three point bending test, the anisotropic nature of fabricated composite experience bending failure due to tensile, compressive, shear or combination of these stresses. The flexural strength and energy absorption properties of the fabricated composites are provided in Table $2^{[25]}$. For each type of composite three samples were tested and the average value is given in the tabulation. From the Figure 5 , it is evident that type III composite have ultimate flexural strength of $223 \mathrm{MPa}$, which is $13 \%$ and $11 \%$ higher than type I and type II composites respectively. This is due to the better adhesive bond between the palmyra palm fibre surface and the matrix. The formation of cusps and scallops are observed in the relatively brittle systems as they are formed from the micro-crack nucleation ahead of the crack tip ${ }^{[26]}$.

For the interlaminar fracture, initial delamination will propagate when local interlaminar stress produced by local bending makes the strain energy release rate $G$ of stratified edge reach or exceed the critical value Gc (interlaminar fracture toughness) ${ }^{[27,28]}$. The palmyra palm fibres exhibit a high elongation at break ${ }^{[19]}$. The high density palmyra palm and aloe vera fibres in the type III composite have better wettability with the resin and the load applied is uniformly distributed within the composite layers. The presence of low

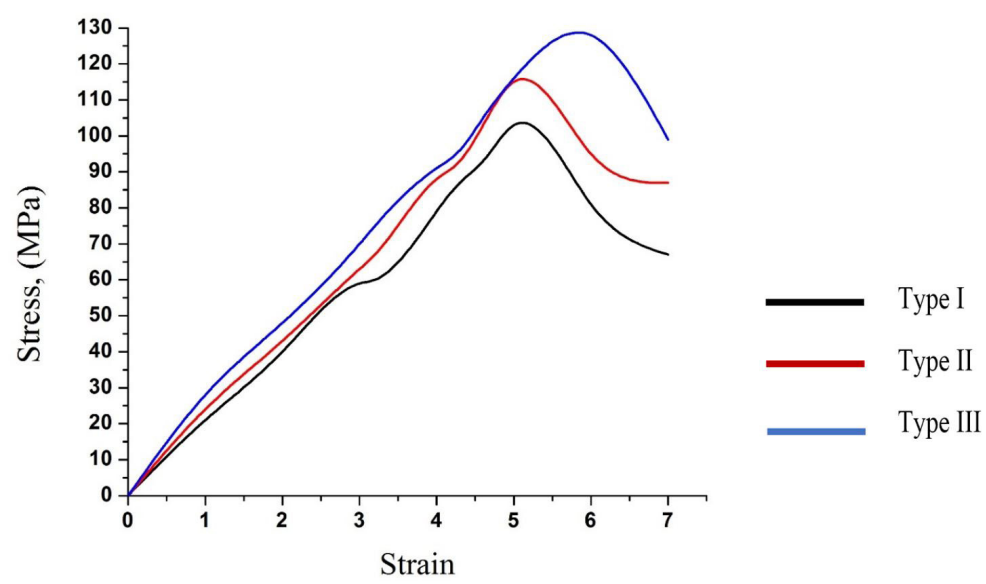

Figure 4. Stress vs. strain for the fabricated composites.

Table 1. Tensile Strength of the fabricated composite specimen.

\begin{tabular}{cccccc}
\hline Composite specimen & Break load (KN) & $\begin{array}{c}\text { Displacement at } \\
\text { break load }(\mathbf{m m})\end{array}$ & Elongation (\%) & $\begin{array}{c}\text { Ultimate tensile } \\
\text { strength (MPa) }\end{array}$ & $\begin{array}{c}\text { Tensile modulus } \\
\text { (MPa) }\end{array}$ \\
\hline (TYPE -I) & 3.68 & 4.5 & 16.38 & 102 & 238.67 \\
(TYPE -II) & 4.7 & 4.6 & 14.54 & 114 & 261.82 \\
(TYPE -III) & 5.5 & 6.4 & 17.26 & 127 & 298.38 \\
\hline
\end{tabular}


Table 2. The flexural test results for three types of composite.

\begin{tabular}{|c|c|c|c|c|}
\hline Composite specimen & Break load (KN) & $\begin{array}{c}\text { Displacement at break } \\
\text { load }(\mathrm{mm})\end{array}$ & Elongation (\%) & $\begin{array}{c}\text { Ultimate flexural } \\
\text { strength (MPa) }\end{array}$ \\
\hline (TYPE -I) & 0.49 & 13.6 & 9.67 & 196.53 \\
\hline (TYPE -II) & 0.44 & 16.2 & 9.93 & 201.64 \\
\hline (TYPE -III) & 0.62 & 19.7 & 11.46 & 223.48 \\
\hline
\end{tabular}

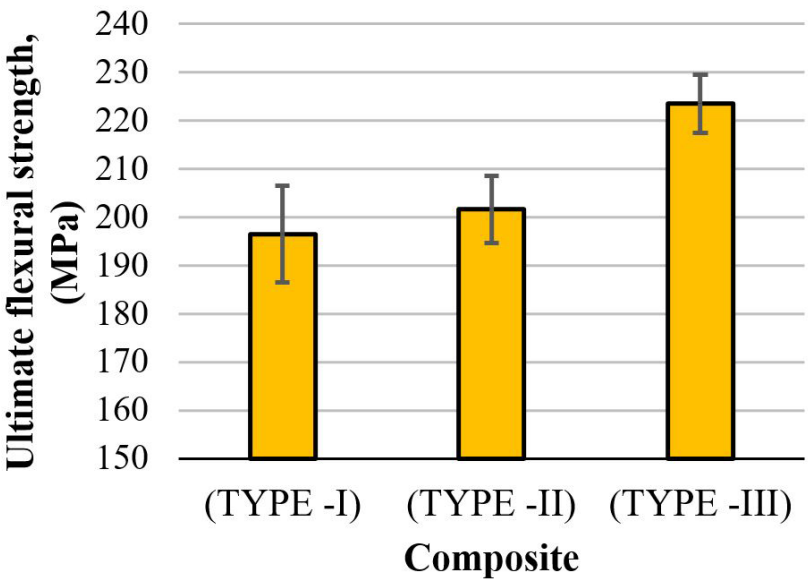

\section{QUltimate flexural strength (MPa)}

Figure 5. Type of composite vs. ultimate flexural strength (MPa).

density bamboo fibres in the composite type I and type II have failed in distributing the load applied. The moderate wettability nature of the bamboo fibre is the prime reason for the failure of the composites. The type of failure observed in type I and type II composites were pure delamination at the bamboo and Kevlar fibre interface which was due to weak bond strength.

\subsection{Dynamic mechanical analysis}

\subsubsection{Storage modulus ( $\left.E^{\prime}\right)$}

In the dynamic mechanical analysis, the applied energy is stored in the material to a certain limit and it is displayed in the form of storage modulus (E'). With the increase in temperature a significant transition is observed in the storage modulus and termed as glass transition temperature ( $\mathrm{Tg})$, beyond which rubbery state occurs as shown in Figure 6 . In the rubbery state, the epoxy resin becomes unstable and the molecular movement occurs as the molecular bond becomes weak, ultimately resulting in the reduction of stiffness $^{[28]}$. E' of composite type III (palmyra palm + aloe vera) have the higher stiffness and increased bond strength with the epoxy resin. The composite type I (bamboo + aloe vera fibres) showed least storage modulus ascribed due to weak fibre-matrix adhesion and lower density of bamboo fibre. It's clear from Figure 6, that the E' tends to become broader in the glassy region, as the components are in close, tightly packed and in frozen state resulting in high storage modulus value below glass transition temperature (Tg). Moreover, the E' curves suffer an intense drop around $85-105{ }^{\circ} \mathrm{C}$ indicating glass/rubbery state transition. But when the temperature increases the composites components tend to show increased molecular mobility, hence, lose their tight packing arrangement, this then gradually decreases the E' values in the rubbery region. However no considerable

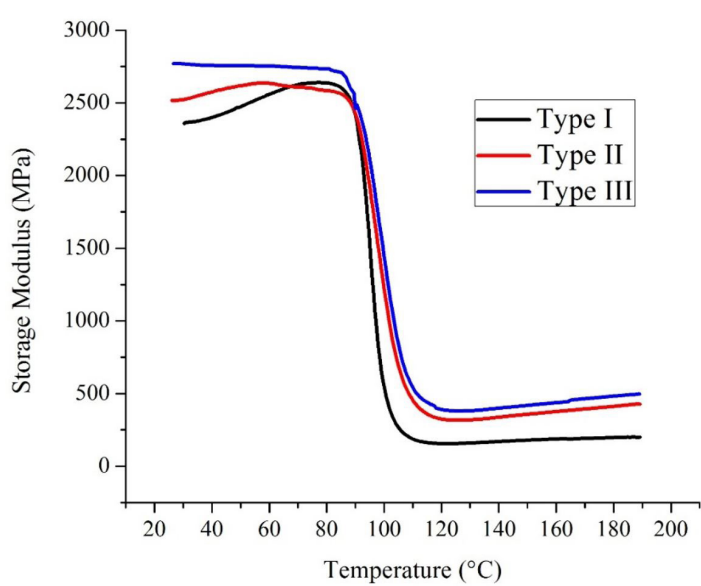

Figure 6. Storage modulus vs. temperature.

changes in the rubbery region were observed for palmyra palm fibre/epoxy composites ${ }^{[29]}$.

\subsubsection{Loss modulus (E”)}

The viscous response of the hybrid composite material is represented by loss modulus (E"). Figure 7 shows the plot between loss modulus and temperature and it can be observed that irrespective of the type of composite, the loss modulus increases initially until a peak and then decreases with the increase in temperature. The fibre type and the fibre wt. \% have a greater influence on the loss modulus of the composites ${ }^{[30]}$. Broadening the curve of the polymer matrix in the composite type III (palmyra palm + aloe vera) indicated that natural fibres played an important role above $\mathrm{Tg}$. The broadening in E" is due to enhancement in chain segment ${ }^{[31]}$. The position and height of the loss modulus 
curve are indicative of the structure and the extent to which the polymer is reinforced, reflecting changes in molecular dynamics in this region ${ }^{[32]}$.

From Figure 7, it is evident that the incorporation of palmyra palm and aloe vera fibres in the type III composite increases the chain segment and causes the widening of the loss modulus peak. The position and height of the loss modulus curve are indicative of the structure and the extent to which the polymer is reinforced, reflecting changes in molecular dynamics in this region ${ }^{[32]}$. The loss modulus peak height was higher for type III composite because of the increased matrix-fibre bond strength and increase in internal friction. This phenomena agrees well with results observed and reported by Saba et al. ${ }^{[29]}$. The type I composite had lowered loss modulus peak height whereas, the composite type III (palmyra palm and aloe vera) displays higher peak height. The maximum value of the loss modulus can be used to determine the maximum rate of heat dissipation, which represents the glass transition temperature ( $\mathrm{Tg}$ ) and this behaviour represents the free movement of the polymer chain at high temperatures ${ }^{[28]}$.

Hybridization of the palmyra palm and aloe vera fibres along with the Kevlar fibres results in a close arrangement between the laminate layers of the composite. The composite type III exhibits improved interfacial adhesion between the fibre and the matrix, which accordingly enriches the structural mobility of the polymer chains. Similar results were observed by Ramesh et al. ${ }^{[33]}$, that combined effect of hybridization and close arrangement between the Kenaf and PET fibres improves the fibre/matrix interfacial adhesion of the composites. The heat dissipated at the interface is due to the frictional resistance generated at the molecular movement. The inclusion of palmyra fibre resulted in an increase in the amount of heat dissipated and results in the transition peak shift to a higher temperature and increases the loss modulus. The enhanced palmyra fibre bond strength with the epoxy matrix restricted the molecular movement ${ }^{[28]}$.

\subsubsection{Damping factor $(\operatorname{Tan} \delta)$}

Damping factors of the composites are dependent on the type of fibres reinforced as shear stress concentration produced at the matrix interface and the dissipation of viscoelastic energy. The presence of laminate fibre in the polymer composite acts as an obstacle, restricting the movement of the polymer chains as a result reducing the molecular motion and overall damping factor of the hybrid composites. If the fibre matrix interface bond is weak, it results in greater values of $\tan \delta$. Damping is reduced for composites type III as the fibre-matrix have a better adhesion. From Figure 8, it is clear that composite type III (palmyra palm + aloe vera) had a lower $\tan \delta$ value. Therefore, when the fibre/matrix interfacial bonding is enhanced, the molecular mobility of the polymer decreases; this consequently results in a reduction in the damping factor. When the degree of stiffness of a composite is increased, the degree of freedom of the polymer chain is limited; this restricts the molecular mobility, resulting in a decrease in the damping value of the material ${ }^{[28]}$.

A positive shift in the damping factor peak values with the increase in temperature was due to the enhanced interfacial adhesion between the palmyra palm + aloe vera

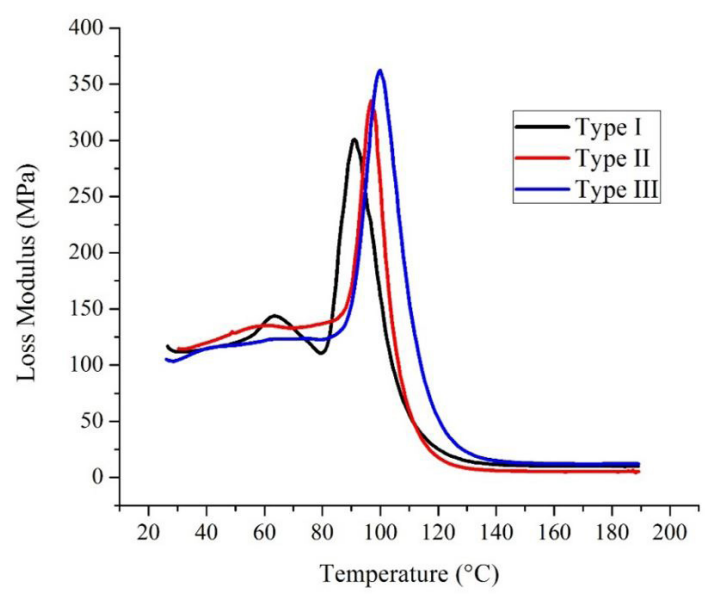

Figure 7. Loss modulus vs. temperature.

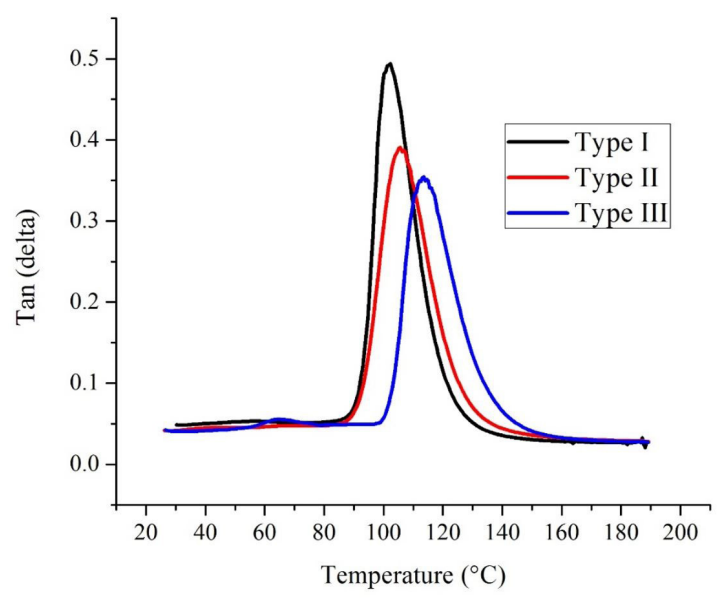

Figure 8. Tan $\delta$ (Damping factor) vs. temperature.

fibres and matrix. The tan $\delta$ peak was narrow for the bamboo reinforced composites compared to palmyra palm fibre reinforced composites. The narrow peak confirms the weak interfacial bond strength similarly the wider peak was due to the formation of higher crosslinking density for the composite type III composites. The results are in accordance with Saba et al. ${ }^{[29]}$. The damping factor is related to molecular movements, viscoelasticity besides the certain defects that contribute towards damping such as dislocations, grain boundaries, phase boundaries and various interfaces ${ }^{[34]}$.

\subsubsection{Morphological analysis using Scanning Electron Microscope (SEM)}

From the scanning electron microscopy images observed for the tensile and flexural test composites to study the fracture surfaces. The hybrid composites are examined for matrix fibre adhesion and understand the failure modes ${ }^{[18]}$. Possible failure that occurs can be either matrix cracking, fibre breaking, matrix-fibre debonding or other possible damages and these damages can be confirmed during the fracture surface detection process ${ }^{[35]}$. Figures 9 and 10 shows the SEM images interfaced with Image J software ${ }^{[36,37]}$ of tensile and flexural test sample surfaces. It is clear from Figure $9 \mathrm{a}$, the fibres with poor wettability are stressed at 

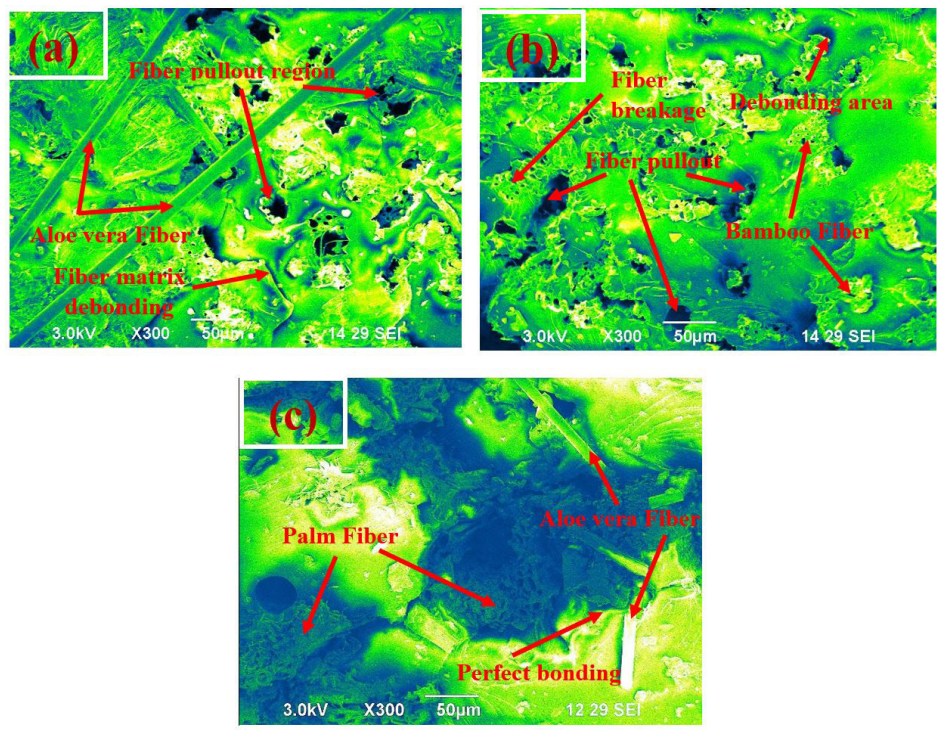

Figure 9. SEM images of tensile test composite (a) type I; (b) type II; (c) type III.
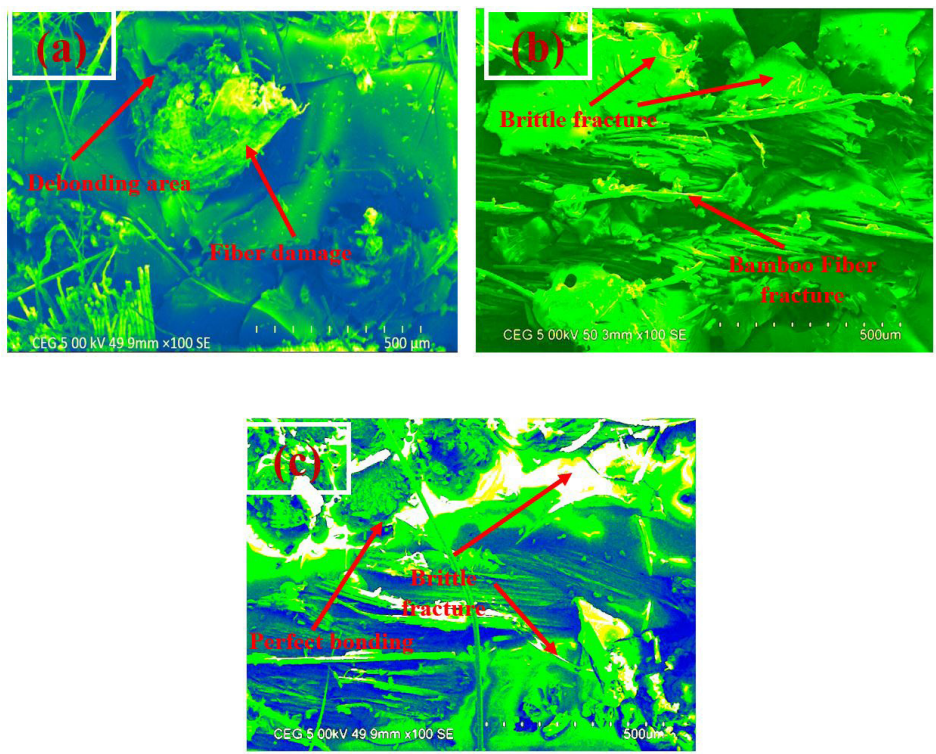

Figure 10. SEM images of flexural test composite (a) type I; (b) type II; (c) type III.

higher tensile loads, resulting in fibre breakage and fibre pullouts. The presence of voids is higher in composite type I when compared to others composites and these voids greatly diminishes the mechanical properties. Similar results have been reported by Arthanarieswaran et al. ${ }^{[37]}$. The Figure 9b shows the voids in the matrix are reduced but not completely eliminated. The addition of palmyra palm fibres has enhanced tight interface bonds with the matrix and the bamboo fibres have poor wettability which is seen in the Figure $9 \mathrm{~b}$. The composite type III (palmyra palm + aloe vera) fibres have better wettability and reduced voids. The palmyra palm fibres have a tight interfacial bond with the matrix with no gap is shown in Figure 9c.

From the Figure 10a, it is clearly seen that there is a clear separation between the fibre and the matrix and this effect is due to the abnormalities in the fibre-matrix bond.
The presence of bamboo fibre in the composite type I, have undergone non-uniform distribution of flexural load. Figure 10b, shows the fractured surface of composite type II (Bamboo + palmyra palm) fibre. The presence of palmyra palm fibre nullified the degrading effect of bamboo fibre and there is no clear separation between the matrix-fibre interfaces. It is clear from the Figure 10c, there is no separation between the fibre-matrix interfaces. The crack propagation in the matrix has been minimized when compared to composite type I (Aloe vera + Bamboo) fibre. The increase in wettability of the natural fibres (Palmyra palm + Aloe vera) in composite type III, increases the interfacial adhesion contributing to the highest flexural strength. The crack propagation is minimized in the composite type III materials. 


\section{Conclusion}

The natural fibre reinforced hybrid composites were successfully fabricated using Vacuum assisted compression moulding along with Kevlar synthetic fibre. The effect of chemically treated aloe vera, bamboo and palmyra palm fibres are studied in detail for their mechanical and dynamic analysis property. The following conclusions have been drawn from the experimental investigation:

- The ultimate tensile strength of composite type III was increased by $12 \%$ and $30 \%$ when compared to composite type I and type II respectively;

- The flexural test results show that composite type III have better flexural strength $223 \mathrm{MPa}$ which $13 \%$ and $11 \%$ greater than composite type I and type II respectively;

- Dynamic mechanical analysis results reveal that composite type III (Palmyra Palm + Aloe vera) had better damping factor due to the enhanced interfacial bond with the matrix;

- Overall, it can be declared that hybridization of composite materials having natural fibres in a well-defined stacking sequence produces better mechanical and flexural properties;

- The composite type III shows better tensile, and flexural properties i.e., the composite with natural fibres such as aloe vera and palmyra palm have better wettability with the matrix and synthetic fibre when compared to bamboo fibre.

\section{References}

1. Jeyapragash, R., Srinivasan, V., \& Sathiyamurthy, S. (2019). Mechanical properties of natural fiber/particulate reinforced epoxy composites: a review of the literature. Materials Today: Proceedings, 22(3), 1223-1227. http://dx.doi.org/10.1016/j. matpr.2019.06.655.

2. Mohammed, L., Ansari, M. N. M., Pua, G., Jawaid, M., \& Islam, M. S. (2015). A review on natural fiber reinforced polymer composite and its applications. International Journal of Polymer Science, 2015, 243947. http://dx.doi.org/10.1155/2015/243947.

3. Saba, N., Jawaid, M., Hakeem, K., Paridah, M., Khalina, A., \& Alothman, O. (2015). Potential of bioenergy production from industrial kenaf (Hibiscus cannabinus L.) based on Malaysian perspective. Renewable \& Sustainable Energy Reviews, 42, 446-459. http://dx.doi.org/10.1016/j.rser.2014.10.029.

4. Saba, N., Jawaid, M., Paridah, M., \& Al-othman, O. (2016). A review on flammability of epoxy polymer, cellulosic and non-cellulosic fiber reinforced epoxy composites. Polymers for Advanced Technologies, 27(5), 577-590. http://dx.doi. org/10.1002/pat.3739.

5. Elanchezhian, C., Vijaya Ramnath, B., Ramakrishnan, G., Rajendrakumar, M., Naveenkumar, V., \& Saravanakumar, M. K. (2018). Review on mechanical properties of natural fiber composites. Materials Today: Proceedings, 5, 1785-1790. http://dx.doi.org/10.1016/j.matpr.2017.11.276.
6. Vijaya Ramnath, B., Elanchezhian, C., Nirmal, P. V., Prem Kumar, G., Santhosh Kumar, V., Karthick, S., Rajesh, S., \& Suresh, K. (2014). Experimental investigation of mechanical behavior of Jute-Flax based glass fiber reinforced composite. Fibers and Polymers, 15(6), 1251-1262.http://dx.doi.org/10.1007/ s12221-014-1251-3.

7. Vijaya Ramnath, B., Manickavasagam, V. M., Elanchezhian, C., Vinodh Krishna, C., Karthik, S., \& Saravanan, K. (2014). Determination of mechanical properties of intra-layer abacajute-glass fiber reinforced composite. Materials \& Design, 60, 643-652. http://dx.doi.org/10.1016/j.matdes.2014.03.061.

8. Reddy, A. C. (2015). Evaluation of curing process for kevlar 49-epoxy composites by mechanical characterization designed for brake liners. International Journal of Scientific Research, 4, 2365-2371. Retrieved in 2020, June 24, from https://www. ijsr.net/archive/v4i4/SUB153699.pdf

9. Chandramohan, D., \& Bharanichandar, J. (2013). Natural fiber reinforced polymer composites for automobile accessories. American Journal of Environmental Sciences, 9(6), 494-504. http://dx.doi.org/10.3844/ajessp.2013.494.504.

10. Srinivasan, V. S., Rajendra Boopathy, S., Sangeetha, D., \& Vijaya Ramnath, B. (2014). Evaluation of mechanical and thermal properties of banana-flax based natural fibre composite. Materials \& Design, 60, 620-627. http://dx.doi.org/10.1016/j. matdes.2014.03.014.

11. Vijaya Ramnath, B., Rajesh, S., Elanchezhian, C., Santosh Shankar, A., Pithchai Pandian, S., Vickneshwaran, S., \& Sundar Rajan, R. (2016). Investigation on mechanical behaviour of twisted natural fiber hybrid composite fabricated by vacuum assisted compression molding technique. Fibers and Polymers, 17(1), 80-87. http://dx.doi.org/10.1007/s12221-016-5276-7.

12. Yan, L., Chouw, N., \& Jayaraman, K. (2014). Flax fibre and its composites: a review. Composites. Part B, Engineering, 56, 296-317. http://dx.doi.org/10.1016/j.compositesb.2013.08.014.

13. Aldousiri, B., Alajmi, M., \& Shalwan, A. (2013). Mechanical properties of palm fibre reinforced recycled HDPE. Advances in Materials Science and Engineering, 2013, 508179. http:// dx.doi.org/10.1155/2013/508179.

14. Das, P. P., \& Vijay Chaudhary, V. (2019). Tribological and dynamic mechanical analysis of bio-composites: a review. Materials Today: Proceedings, 25(4), 729-734. http://dx.doi. org/10.1016/j.matpr.2019.08.233

15. Chaitanya, S., \& Singh, I. (2016). Novel Aloe Vera fiber reinforced biodegradable composites: development and characterization. Journal of Reinforced Plastics and Composites, 35(19), 14111423. http://dx.doi.org/10.1177/0731684416652739.

16. Sampath, P., \& Santhanam, S. K. V. (2019). Effect of moringa and bagasse ash filler particles on basalt/epoxy composites. Polímeros: Ciência e Tecnologia, 29(3), e2019034. http:// dx.doi.org/10.1590/0104-1428.01219.

17. Karaduman, Y., Onal, L., \& Rawal, A. (2015). Effect of stacking sequence on mechanical properties of hybrid flax/jute fibers reinforced thermoplastic composites. Polymer Composites, 36(12), 2167-2173. http://dx.doi.org/10.1002/pc.23127.

18. Nunes, J. P., Pouzada, A. S., \& Bernardo, C. A. (2002). The use of a three-point support flexural test to predict the stiffness of anisotropic composite plates in bending. Polymer Testing, 21(1), 27-33. http://dx.doi.org/10.1016/S0142-9418(01)00040-X.

19. Li, J., Zhang, X., Zhu, J., Yu, Y., \& Wang, H. (2020). Structural, chemical, and multi-scale mechanical characterization of waste windmill palm fiber (Trachycarpus fortunei). Journal of Wood Science, 66(1), 8. http://dx.doi.org/10.1186/s10086-020-1851-z.

20. Saba, N., Jawaid, M., Alothman, O. Y., \& Paridah, M. T. (2016). A review on dynamic mechanical properties of natural fibre reinforced polymer composites. Construction \& 
Building Materials, 106, 149-159. http://dx.doi.org/10.1016/j. conbuildmat.2015.12.075.

21. Gupta, M. K., \& Srivastava, R. K. (2016). Mechanical Properties of Hybrid Fibers-Reinforced Polymer Composite: A Review. Polymer-Plastics Technology and Engineering, 55(6), 626-642. http://dx.doi.org/10.1080/03602559.2015.1098694.

22. Niranjan, R. R., Junaid Kokan, S., Sathya Narayanan, R., Rajesh, S., Manickavasagam, V. M., \& Ramnath, B. V. (2013). Fabrication and Testing of Abaca Fibre Reinforced Epoxy Composites for Automotive Applications. Advanced Materials Research, 718-720, 63-68. http://dx.doi.org/10.4028/www. scientific.net/AMR.718-720.63.

23. Gheith, M. H., Aziz, M. A., Ghori, W., Saba, N., Asim, M., Jawaid, M., \& Alothman, O. Y. (2019). Flexural, thermal and dynamic mechanical properties of date palm fibres reinforced epoxy composites. Journal of Materials Research and Technology, 8(1), 853-860. http://dx.doi.org/10.1016/j.jmrt.2018.06.013.

24. Li, X. (2004). Physical, chemical, and mechanical properties of bamboo and its utilization potential for fibre board manufacturing (Master's theses). Louisiana State University and Agricultural and Mechanical College, USA. Retrieved in 2020, June 24, from https://digitalcommons.lsu.edu/gradschool_theses/866

25. Li, S., Zheng, T., Li, Q., Hu, Y., \& Wang, B. (2019). Flexural and energy absorption properties of natural-fiber reinforced composites with a novel fabrication technique. Composite Communications, 16, 124-131. http://dx.doi.org/10.1016/j. coco.2019.09.005.

26. Gilchrist, M. D., \& Svensson, N. (1995). A fractographic analysis of delamination within multidirectional carbon/epoxy laminates. Composites Science and Technology, 55(2), 195-207. http://dx.doi.org/10.1016/0266-3538(95)00099-2.

27. Xie, X., Zhou, Z., \& Yan, Y. (2019). Flexural properties and impact behaviour analysis of bamboo cellulosic fibers filled cement based composites. Construction \& Building Materials, 220, 403-414. http://dx.doi.org/10.1016/j.conbuildmat.2019.06.029.

28. Ahmad, M. A. A., Abdul Majid, M. S., Ridzuan, M. J. M., Mazlee, M. N., \& Gibson, A. G. (2018). Dynamic mechanical analysis and effects of moisture on mechanical properties of interwoven hemp/polyethylene terephthalate (PET) hybrid composites. Construction \& Building Materials, 179, 265-276. http://dx.doi.org/10.1016/j.conbuildmat.2018.05.227.

29. Saba, N., Paridah, M. T., Abdan, K., \& Ibrahim, N. A. (2016). Dynamic mechanical properties of oil palm nano filler/kenaf/epoxy hybrid nanocomposites. Construction \& Building Materials, 124, 133-138. http://dx.doi.org/10.1016/j. conbuildmat.2016.07.059.
30. Shanmugam, D., \& Thiruchitrambalam, M. (2013). Static and dynamic mechanical properties of alkali treated unidirectional continuous Palmyra Palm Leaf Stalk Fiber/jute fiber reinforced hybrid polyester composites. Materials \& Design, 50, 533-542. http://dx.doi.org/10.1016/j.matdes.2013.03.048.

31. Ornaghi, H. L., Jr., Silva, H. S. P., Zattera, A. J., \& Amico, S. C. (2011). Hybridization effect on the mechanical and dynamic mechanical properties of curaua composites. Materials Science and Engineering A, 528(24), 7285-7289. http://dx.doi. org/10.1016/j.msea.2011.05.078.

32. Dan-Mallam, Y., Hong, T. W., \& Abdul Majid, M. S. (2015). Mechanical characterization and water absorption behaviour of interwoven Kenaf/PET fibre reinforced epoxy hybrid composite. International Journal of Polymer Science, 2015, 371958. http://dx.doi.org/10.1155/2015/371958.

33. Ramesh, M., Palanikumar, K., \& Hemachandra Reddy, K. (2017). Plant fibre based bio-composites: sustainable and renewable green materials. Renewable \& Sustainable Energy Reviews, 79, 558-584. http://dx.doi.org/10.1016/j.rser.2017.05.094.

34. Safri, S. N. A., Sultan, M. T. H., Jawaid, M., \& Abdul Majid, M. S. (2019). Analysis of dynamic mechanical, low-velocity impact and compression after impact behaviour of benzoyl treated sugar palm/glass/epoxy composites. Composite Structures, 226, 111308. http://dx.doi.org/10.1016/j.compstruct.2019.111308.

35. Schindelin, J., Arganda-Carreras, I., Frise, E., Kaynig, V., Longair, M., Pietzsch, T., Preibisch, S., Rueden, C., Saalfeld, S., Schmid, B., Tinevez, J. Y., White, D. J., Hartenstein, V., Eliceiri, K., Tomancak, P., \& Cardona, A. (2012). Fiji: an open-source platform for biological-image analysis. Nature Methods, 9(7), 676-682. http://dx.doi.org/10.1038/nmeth.2019. PMid:22743772.

36. Dhanashekar, M., \& Kumar, V. S. (2018). Tribological behaviour of squeeze cast AL-SI7MG/SIC/GR hybrid composites. Journal of the Balkan Tribological Association, 24(1), 106121. Retrieved in 2020, June 24, from https://scibulcom.net/ en/article/HuylZtXN2S7ndz9HQyTb

37. Arthanarieswaran, V. P., Kumaravel, A., \& Kathirselvam, M. (2014). Evaluation of mechanical properties of banana and sisal fiber reinforced epoxy composites: influence of glass fiber hybridization. Materials \& Design, 64, 194-202. http:// dx.doi.org/10.1016/j.matdes.2014.07.058.

Received: June 24, 2020

Revised: Jan. 28, 2021

Accepted: Feb. 18, 2021 